\title{
Exportaciones del sector automotor brasileño al Mercado Común del Sur: ¿desviación de comercio o reducción de costos?
}

\author{
André Filipe Zago de Azevedo y Angélica Massuquetti
}

RESUMEN

El sector automotor es uno de los sectores donde más ha crecido el comercio entre los miembros del MERCOSUR. Aquí se examina la eventual desviación de comercio en ese sector durante el período 1991-2010, suponiendo la reducción de costos de los productos dada la expansión del mercado. El análisis se basa en los conceptos de reducción de costos y supresión de comercio acuñados por Corden (1972), con que se captan los efectos de las economías de escala. Para verificar si el bloque evoluciona de acuerdo con las ventajas comparativas, se utilizan los índices de orientación regional y de ventajas comparativas reveladas en forma conjunta. Los resultados sugieren un aumento de la eficiencia en el caso de los productos del sector automotor, cuyas exportaciones desde el Brasil al MERCOSUR fueron más dinámicas, pues el mercado ampliado y relativamente protegido permitió aprovechar las economías de escala características de la industria automotriz.

PALABRAS CLAVE

CLASIFICACIÓN JEL

AUTORES
Automóviles, exportaciones, Brasil, MERcosur, política comercial, comercio intrarregional, costos, estadísticas comerciales

F12, F13, F15

André Filipe Zago de Azevedo es profesor del Programa de Posgrado en Economía de la Universidade do Vale do Rio dos Sinos (unisinos), Brasil. aazevedo@unisinos.br

Angélica Massuquetti es profesora del Programa de Posgrado en Economía de la Universidade do Vale do Rio dos Sinos (unisinos), Brasil. angelicam@unisinos.br 


\section{I}

\section{Introducción}

El Mercado Común del Sur (MerCosur) se creó con el objetivo de ampliar la integración económica de sus países miembros, especialmente por medio de la eliminación preferencial de barreras arancelarias en el comercio dentro del bloque. Mediante el Tratado de Asunción, firmado por la Argentina, el Brasil, el Paraguay y el Uruguay el 26 de marzo de 1991, se ratificó la decisión de los cuatro países de ampliar las dimensiones de sus mercados nacionales para mejorar su inserción en el orden económico internacional, cada vez más marcado por la regionalización. El sector automotor fue uno de los más importantes en el proceso de integración: el flujo de comercio dentro del bloque aumentó considerablemente, no obstante la ausencia de un aparato legal que asegurara el libre comercio entre sus miembros. En 1997, las exportaciones hacia el MERCOSUR constituyeron casi el $50 \%$ de las exportaciones del sector automotor del Brasil.

Desde el comienzo del proceso de integración, algunos autores han señalado que el crecimiento del comercio en el sector automotor entre los países del bloque obedecería a una desviación del comercio (Yeats, 1997). Como es sabido, existe una propensión a las economías de escala en el sector automotor (Senhoras, 2005; Casotti y Goldenstein, 2008) y la ampliación del mercado a raíz de la formación del bloque puede haber contribuido a aumentar el grado de competitividad de la producción dentro del grupo de países miembros. En ese sentido, es importante tener en cuenta otros conceptos empleados en la literatura para examinar los efectos de los bloques económicos en presencia de economías de escala, sobre todo los denominados "reducción de costos" y "supresión de comercio" propuestos por Corden (1972).

El objetivo principal de este artículo consiste en cuestionar la existencia de desviación de comercio en el sector automotor del MERCOSUR, debido a la presencia de economías de escala en el sector, y proponer un análisis alternativo, basado en los conceptos sugeridos por Corden (1972). Para ello se analizan los 76 productos con códigos de seis dígitos del capítulo 87 del Sistema Armonizado, con miras a identificar a aquellos respecto de los cuales hubo una reorientación de los flujos comerciales del sector hacia el interior del bloque, y analizar la evolución de su competitividad en el período 1991-2010. Mientras que el grado de reorientación comercial de los productos del sector automotor se evalúa mediante el índice de orientación regional (IOR), la competitividad se mide según el índice de ventajas comparativas reveladas (IVCR). De ese modo, en caso de incrementarse la competitividad de los productos del sector automotor que registraron la mayor variación de comercio hacia dentro del bloque, se puede afirmar que este estaría reduciendo los costos de los productos de ese sector, incluso aunque en ellos incida un elevado grado de proteccionismo con respecto a los países que no pertenecen al MERCOSUR.

El trabajo consta de seis secciones, incluida esta Introducción. En la segunda sección se describen las principales medidas adoptadas por el bloque en relación con el sector automotor, tanto para regular el comercio intrazona como para establecer el grado de protección con respecto a las importaciones extrazona. Mientras que en la tercera sección se abordan aspectos teóricos y empíricos relacionados con los efectos de los bloques económicos en presencia de economías de escala, en la cuarta se presenta la metodología adoptada. En la quinta sección se examina la existencia de reducción de costos en el MERCOSUR a través del IOR y del IVCR, y en la sexta sección se presentan las consideraciones finales. 


\section{II}

\section{El MERCOSUR y la legislación del régimen automotor}

Los casos más destacados de productos excluidos del programa de liberalización dentro del MERCOSUR se refieren al sector automotor y al azúcar ${ }^{1}$. En la fase inicial de integración, el comercio en el sector automotor se reguló mediante el Acuerdo de Complementación Económica $\mathrm{N}^{\circ} 14$ (ACE), cuyo objetivo era establecer el mercado común y promover la complementación económica de la industria, aumentando la capacidad competitiva de los países signatarios. Este acuerdo, vigente desde el 20 de diciembre de 1990, fue y es una de las herramientas de equilibrio dinámico entre la Argentina y el Brasil, y se modifica mediante protocolos adicionales. Por otra parte, por medio de la decisión $\mathrm{N}^{\circ} 29$ de 1994 se establecieron tres elementos básicos del régimen automotor del bloque, que se adoptaría en enero de 2000: i) liberalización total del comercio intrazona para los productos del sector automotor; ii) Arancel Externo Común (AEC), y iii) ausencia de incentivos nacionales que distorsionen la competitividad en la región. Las reglas para el comercio intrazona y respecto de las importaciones desde fuera del bloque son dos aspectos que merecen especial atención.

Desde su creación, el comercio entre los miembros del bloque puede caracterizarse como un comercio administrado sobre la base de contenidos regionales mínimos, requisitos de equilibrio de la balanza comercial y entrada condicionada (BID, 1996). La liberalización del comercio del sector automotor entre los países del MERCOSUR se ha postergado continuamente debido a divergencias con respecto al régimen de este sector y en su lugar se ha mantenido el comercio administrado. A comienzos de la década de 2000 se inauguró la Política Automotriz Común del bloque, que establece

\footnotetext{
${ }^{1}$ En los productos del régimen automotor se incluyen automóviles, vehículos comerciales livianos de hasta 1,5 toneladas, omnibuses y camiones, máquinas agrícolas y viales, piezas para vehículos, chasis con motor, remolques, semirremolques y piezas para producción y para el mercado de repuestos. Con respecto al azúcar, se estipuló un período de transición hasta el 1 de enero de 2001 — en el que tendría lugar la liberalización del comercio dentro del bloque- acompañado de medidas orientadas a la eliminación de políticas públicas que distorsionaran la producción y la exportación de este producto en el bloque. Sin embargo, hasta comienzos de 2014, el comercio todavía estaba sujeto a aranceles de importación.
}

la regulación del comercio intrazona mediante el coeficiente de desviación de las exportaciones (flex), mecanismo que permite un determinado desequilibrio entre las exportaciones del sector. Entre el 1 de agosto de 2000 y el 31 de diciembre de 2005, de acuerdo con el $30^{\circ}$ Protocolo Adicional al ACE-14, el intercambio comercial de productos del sector quedó exento de aranceles, admitiéndose una desviación máxima del $3 \%$ del volumen de intercambio, que se acrecentaría al $10 \%$ en 2003. Las exportaciones que excedieran el límite autorizado se gravarían con el 70\% del AEC en el caso de todos los tipos de vehículos y con el $75 \%$ del AEC en el caso de las piezas².

No obstante, las reglas se modificaron nuevamente en 2002 mediante el $31^{\circ}$ Protocolo Adicional al ACE-14, en el que se cambiaban los límites al volumen de comercio en valores medidos en dólares. Así, se estableció que por cada dólar exportado desde la Argentina al Brasil, el Brasil podría exportar 2 dólares a la Argentina sin el pago de alícuotas de impuesto en 2002, manteniéndose las alícuotas detalladas anteriormente en caso de superarse el límite definido. Poco a poco el flex convergería a 2,6 en 2005 y, finalmente, en 2006 habría libre comercio. Sin embargo, las autoridades argentinas insistieron en el mantenimiento de los límites al libre comercio mediante el régimen de flex, mientras no fuera posible un intercambio bilateral más equilibrado con el Brasil. De este modo, en julio de 2006 se publicó el $35^{\circ}$ Protocolo Adicional al ACE-14, válido desde julio de 2006 a junio de 2008 , en el que se modificaba el coeficiente de desviación anual a 1,95 , sin pago de impuestos. La pena para las exportaciones que superaran el límite se mantuvo en el $75 \%$ y el $70 \%$ de la alícuota del AEC en el caso de las piezas y de los automóviles, respectivamente (BID, 2008).

Después de intensas negociaciones, en junio de 2008 se aprobó el $38^{\circ}$ Protocolo Adicional al ACE-14, que fijaba el inicio del libre comercio dentro del bloque para julio de 2013, pese a la presión de las autoridades

\footnotetext{
2 Mediante el acuerdo se fijó también un contenido regional mínimo del $60 \%$ (de partes y piezas) para que el producto quedara exento de aranceles en las transacciones bilaterales.
} 
brasileñas que deseaban un plazo menor ${ }^{3}$. La novedad fue el establecimiento de un flex asimétrico: el límite para el déficit comercial en el sector se fijó en 1,95 en el caso de la Argentina y en 2,5 en el del Brasil. Si se supone que esta vez se cumplirá con el acuerdo, habrán pasado 22 años, entre 1991 y 2013, para el cumplimiento de lo dispuesto en el Tratado de Asunción.

Además de la ausencia de libre comercio dentro del bloque, el grado de proteccionismo en relación con las importaciones del sector automotor desde otros países ha sido siempre elevado en el ámbito del MERCOSUR. Excepto por un breve período inmediatamente posterior a su formación, cuando era del $20 \%$, el límite superior

\footnotetext{
3 El fin del comercio administrado en el sector automotor en el MERCOSUR debe beneficiar más a la industria automotriz brasileña, cuya producción es muy superior a la de la Argentina. Mientras que la producción brasileña mostró una trayectoria ascendente entre 1991 y 2006, alcanzando aproximadamente a tres millones de vehículos en 2006, la producción de automóviles en la Argentina fue mucho más inestable, llegando a un nivel de alrededor de 500.000 vehículos ese mismo año.
}

del AEC del bloque para la mayoría de los productos ha correspondido al valor máximo permitido por la Organización Mundial del Comercio (OMC). Así, a partir de la década de 2000, el AEC se fijó en un 35\% para los vehículos en general y en un $14 \%$ para las máquinas agrícolas y las piezas.

Kume y Piani (2005) confirmaron el fuerte proteccionismo practicado en el sector automotor del bloque, al calcular la protección nominal y efectiva del AEC del MERCOSUR en todos los sectores de actividades en 2006 (véase el cuadro 1). Los productos del sector automotor (automóviles, camiones y omnibuses) presentaban el mayor grado de protección, tanto en términos nominales como efectivos. El arancel nominal del sector era del $34 \%$, muy superior al arancel medio de apenas un $12,4 \%$. La protección efectiva era incluso mayor, del $124 \%$, mientras que la media de todos los sectores era de apenas un $17,2 \%$. Además de gozar de una protección efectiva muy elevada, el sector dispone de incentivos fiscales y financieros estaduales y, especialmente, de un régimen automotor a nivel federal.

MERCOSUR: Arancel Externo Común (AEC) nominal y efectivo, por actividad, 2006

(En porcentajes)

\begin{tabular}{|c|c|c|c|}
\hline Código & Actividad & $\begin{array}{l}\text { Arancel Externo } \\
\text { Común nominal }\end{array}$ & $\begin{array}{l}\text { Arancel Externo } \\
\text { Común efectivo }\end{array}$ \\
\hline 1 & Agropecuaria & 3,78 & 2,93 \\
\hline 2 & Extractiva mineral & 3,95 & 1,72 \\
\hline 3 & Petróleo y carbón & 0,00 & $-1,82$ \\
\hline 4 & Productos minerales y metálicos & 11,47 & 13,29 \\
\hline 5 & Siderurgia & 7,98 & 12,55 \\
\hline 6 & Metalurgia de metales no ferrosos & 9,78 & 10,28 \\
\hline 7 & Otros productos metalúrgicos & 15,80 & 21,25 \\
\hline 8 & Máquinas y tractores & 13,85 & 14,22 \\
\hline 9 & Material eléctrico & 15,99 & 19,99 \\
\hline 10 & Equipos electrónicos & 13,10 & 12,86 \\
\hline 11 & Automóviles, camiones y omnibuses & 33,97 & 123,96 \\
\hline 12 & Otros vehículos y piezas & 13,81 & 14,22 \\
\hline 13 & Madera y mobiliario & 10,97 & 13,10 \\
\hline 14 & Celulosa, papel y gráfica & 11,94 & 12,71 \\
\hline 15 & Caucho & 12,84 & 14,70 \\
\hline 16 & Fabricación de elementos químicos & 12,83 & 13,91 \\
\hline 17 & Refinación de petróleo & 4,58 & 5,33 \\
\hline 18 & Productos químicos diversos & 8,80 & 10,62 \\
\hline 19 & Farmacéutica y perfumería & 10,00 & 9,95 \\
\hline 20 & Artículos de plástico & 16,54 & 20,59 \\
\hline 21 & Textil & 16,39 & 21,77 \\
\hline 22 & Prendas de vestir & 19,58 & 22,28 \\
\hline 23 & Cueros y calzado & 14,23 & 15,75 \\
\hline 24 & Industria del café & 11,33 & 11,73 \\
\hline 25 & Procesamiento de productos vegetales & 12,09 & 22,17 \\
\hline 26 & Faena de animales & 9,76 & 9,81 \\
\hline 27 & Industria de productos lácteos & 15,57 & 16,57 \\
\hline 28 & Azúcar & 16,00 & 16,90 \\
\hline 29 & Fabricación de aceites vegetales & 8,72 & 9,90 \\
\hline
\end{tabular}


Cuadro 1 (conclusión)

\begin{tabular}{|c|c|c|c|}
\hline Código & Actividad & $\begin{array}{l}\text { Arancel Externo } \\
\text { Común nominal }\end{array}$ & $\begin{array}{l}\text { Arancel Externo } \\
\text { Común efectivo }\end{array}$ \\
\hline 30 & Bebidas y otros productos alimentarios & 15,69 & 23,64 \\
\hline \multirow{3}{*}{31} & Media simple & 12,44 & 17,19 \\
\hline & Mínimo & 0,00 & $-1,82$ \\
\hline & Máximo & 33,70 & 123,96 \\
\hline
\end{tabular}

Fuente: H. Kume y G. Piani, "MErcosul: o dilema entre união aduaneira e área de livre-comércio", Revista de Economia Política, vol. 25, $\mathrm{N}^{\circ}$ 4, São Paulo, 2005.

MERCOSUR: Mercado Común del Sur.

\section{III}

\section{Desviación de comercio o reducción de costos:}

\section{teoría y medición}

La elaboración de estudios sobre los efectos de los acuerdos de liberalización preferencial del comercio cobró especial importancia en la década de 1990 debido a la proliferación de ese tipo de acuerdos a nivel mundial. El MERCOSUR no fue la excepción y varios autores examinaron los efectos del bloque en una serie de variables a partir de diversas metodologías (entre ellos Piani, 1998; Negri, 1999; Machado y Cavalcanti, 1999; Tigre y otros, 1999; Sarti, 2001; Sica, 2005).

Incluso antes de la ampliación de las controversias entre los países del MERCosur, Yeats (1997) comparó los índices de orientación regional y de ventajas comparativas reveladas en el período 1988-1994 y llegó a la conclusión de que la estructura de comercio intrabloque estaba distorsionada. El autor encontró señales de desviación de comercio después de la formación del bloque respecto de aquellos productos con mayor crecimiento de la orientación regional de su comercio, incluidos los del sector automotor, y lo atribuyó a los altos aranceles aplicados a las importaciones desde otros países, que garantizarían a los productos del bloque un mercado protegido. Esa visión coincide con el síndrome "este mercado es nuestro" propuesto por Bhagwati (1993), donde se sostiene que la formación de un bloque en un ambiente en que los productores desempeñan un papel relevante en la determinación de las políticas comerciales puede conducir a un aumento del proteccionismo con respecto a los países ubicados fuera del bloque.
No obstante, el análisis de Viner (1950), basado en los conceptos de creación y desviación de comercio, debería aplicarse solo a los sectores que cuentan con estructuras de mercado de competencia perfecta y carecen de economías de escala. Corden (1972) mostró que, además de los efectos tradicionales descritos por Viner, la existencia de economías de escala en sectores caracterizados por una estructura de mercado de competencia imperfecta produciría dos efectos adicionales en el bienestar. El primero consiste en la "reducción de costos" y ocurre cuando la integración se traduce en un incremento de la escala de producción. Al actuar en un mercado ampliado, aumenta la eficiencia de las empresas y se reducen sus costos medios de producción, como se puede visualizar en el gráfico 1.

Como se puede observar, en la situación de equilibrio inicial (e0) hay un arancel de importación a medida $\left(\mathrm{t}=\mathrm{P}_{\mathrm{A}}-\mathrm{P}_{\mathrm{C}}\right)$ (o sea, aquel que impide las importaciones) que desvía el consumo de un determinado producto en el país A hacia el punto $\mathrm{d}_{0}$, suplido por la producción interna. Con la formación de una unión aduanera entre el país A y otros países menos eficientes en la fabricación de ese producto, se establece un arancel externo común, también a medida, pero inferior al arancel vigente antes de la formación del bloque $\left(\mathrm{P}_{\mathrm{UA}}-\mathrm{P}_{\mathrm{C}}\right)$. En presencia de economías de escala, la ampliación del mercado debido a la formación de un bloque conduce a una disminución del costo medio de las empresas que operan en el país A, que permite a su vez la reducción del arancel de 
importación. Se produce entonces un nuevo equilibrio (e1), en que el país A suministra a todos los países del bloque la cantidad $\mathrm{d}_{2}$ del producto y destina la cantidad $\mathrm{d}_{1}$ al consumo interno. Cabe señalar que, si bien el país extranjero $C$ es más eficiente que el país $\mathrm{A}\left(\mathrm{P}_{\mathrm{C}}\right)$ en ambas situaciones, el arancel de importación a medida impide las importaciones. Sin embargo, la ampliación del mercado en presencia de economías de escala conduce a un incremento de la eficiencia económica, que permite aminorar el arancel de importación y el precio cobrado a los consumidores del país A. Las ganancias de bienestar se muestran en las áreas A y B, que reflejan el crecimiento del excedente del consumidor a causa de la disminución de los precios de $\mathrm{P}_{\mathrm{A}}$ a $\mathrm{P}_{\mathrm{UA}}$. Estos aspectos caracterizan la situación de "reducción de costos" propuesta por Corden (1972).

GRÁFICO 1

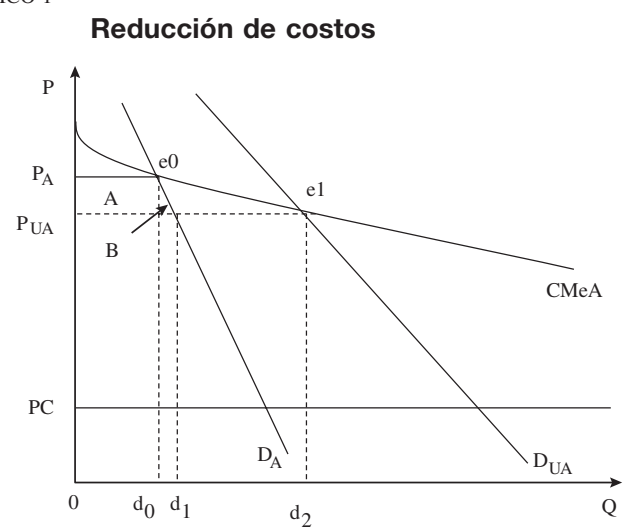

Fuente: W.M. Corden, "Economies of scale and customs union theory", Journal of Political Economy, vol. 80, ํㅜ 3, Chicago, The University of Chicago Press, 1972; y A. Panagariya, "The regionalism debate: an overview", World Economy, vol. 22, № 4 , Wiley, 1999.

El segundo efecto corresponde a la "supresión de comercio", que tiene lugar cuando la reducción de costos derivada de la integración permite que las empresas que operan dentro del bloque se vuelvan más eficientes, pero no lo suficiente como para suplantar a sus rivales fuera de este. Esto último ocurre solo gracias a las medidas proteccionistas que el bloque impone a las importaciones más competitivas desde otros países. La nueva situación se ilustra en el gráfico 2. En el equilibrio inicial $\left(\mathrm{e}_{0}\right)$, el arancel de importación $\left(t=\mathrm{P}_{\mathrm{TC}}-\mathrm{P}_{\mathrm{C}}\right)$ es menor que el arancel a medida, de modo que el país A puede importar $\mathrm{d}_{2}$ desde el país $\mathrm{C}$ al precio $\mathrm{P}_{\mathrm{TC}}$. En ese contexto, el bien de referencia no se produce en el país A y todo lo que se consume se importa desde el país $\mathrm{C}$, que es más eficiente. Con la formación de la unión aduanera se produce un nuevo equilibrio $\left(\mathrm{e}_{1}\right)$ : se establece un arancel externo común a medida $\left(\mathrm{P}_{\mathrm{UA}}-\mathrm{P}_{\mathrm{C}}\right)$, mayor que el arancel vigente antes de la formación del bloque, que se traduce en un incremento del precio del producto. Como consecuencia del precio $\mathrm{P}_{\mathrm{UA}}$, el país comienza a producir $\mathrm{d}_{1}$ para consumo interno y a exportar $\mathrm{d}_{1} \mathrm{~d}_{3}$. Esto redunda en pérdidas derivadas de la supresión de comercio causada por la sustitución de un productor externo eficiente (país $\mathrm{C}$ ) por un productor interno menos eficiente (país A). En este caso se observan pérdidas de bienestar relacionadas con el excedente del consumidor (áreas C y D) y los ingresos del gobierno (áreas E y F).

GRÁFICO 2

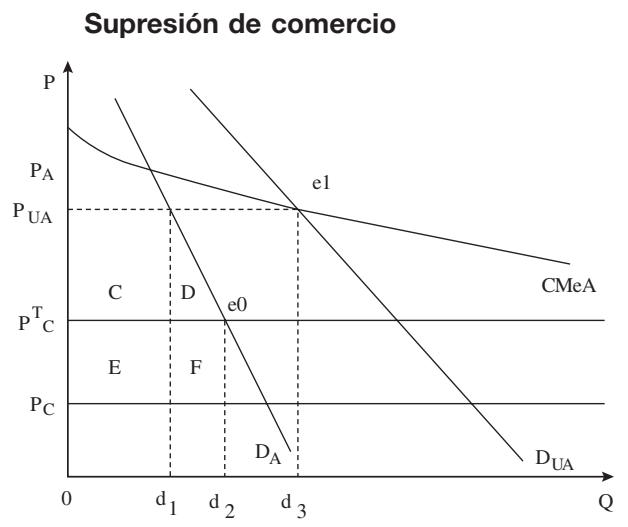

Fuente: W.M. Corden, "Economies of scale and customs union theory", Journal of Political Economy, vol. 80, $\mathrm{N}^{\circ} 3$, Chicago, The University of Chicago Press, 1972; y A. Panagariya, "The regionalism debate: an overview", World Economy, vol. 22, $\mathrm{N}^{\circ} 4$, Wiley, 1999.

En la literatura se indica profusamente la presencia de economías de escala en el sector automotor, que se caracterizaría por su organización en un oligopolio global con elevadas ganancias de economías de escala (Casotti y Goldenstein, 2008; Senhoras, 2005). La presencia de economías de escala y de aglomeración conduce a la concentración de grandes empresas en determinadas regiones geográficas (Gabriel y otros, 2011). El sector automotor es uno de los pocos que presentarían esas características en el MERCosur (Giordano y Santiso, 1999).

En tal sentido, una forma de establecer la presencia de los dos efectos adicionales de las economías de escala sugeridos por Corden (1972) consiste en el examen conjunto del índice de orientación regional (IOR) y el índice de ventajas comparativas reveladas (IVCR). El incremento de ambos índices después de la formación del bloque, combinado con un aumento del IVCR de un 
valor inferior a 1 a un valor superior a 1, indicaría la situación de "reducción de costos". El acrecentamiento de los dos índices, sin que el IVCR alcance el valor unitario, sería una señal de "supresión de comercio". En ambos

\section{IV}

\section{Metodología}

En este artículo se analizan los 76 productos con códigos de seis dígitos del capítulo 87 del Sistema Armonizado para establecer la existencia de reducción de costos o supresión de comercio en el sector automotor del MERCOSUR durante el período 1991-20104. Para ello se utilizan los mismos indicadores sugeridos por Yeats (1997), pero con una interpretación modificada por la presencia de economías de escala. El análisis de la orientación del comercio se realiza mediante el IOR, mientras que la competitividad se mide de acuerdo con el IVCR. La determinación de los productos con mayor dinamismo exportados por el Brasil se basa en dos criterios: i) la mayor variación absoluta del IOR a lo largo del período analizado, y ii) un flujo de exportaciones hacia el bloque por un valor de 50.000 dólares o más al inicio del período de referencia ${ }^{5}$. A diferencia del análisis de Yeats, en este trabajo se examinan los efectos del sector automotor en el comercio dentro del bloque en el marco de un ambiente dinámico y no estático, que permite la influencia de economías de escala. Los datos relativos a las exportaciones brasileñas y mundiales de los productos del sector automotor con códigos de seis dígitos del Sistema Armonizado (capítulo 87) provienen de la Agencia Brasileña de Promoción de Exportaciones e Inversiones (Apex-Brasil).

El IOR es una razón entre dos proporciones y se obtiene al dividir la participación de las exportaciones de un producto con respecto a las exportaciones totales del país hacia el bloque económico por la participación de las exportaciones de ese producto en el total exportado fuera del bloque. El índice se sitúa en un intervalo de cero a infinito, en el que la unidad indica una misma tendencia para exportar el producto a miembros y no miembros, mientras que los valores crecientes y superiores a 1 ,

\footnotetext{
4 Véase la descripción de los productos del capítulo 87 en el anexo.

5 El límite mínimo se estableció para evitar que los resultados fueran sesgados hacia productos con baja participación en la pauta de exportaciones al inicio del período de análisis.
}

casos, dada la prerrogativa de la existencia de economías de escala derivadas de un incremento de la producción, es necesario que el valor de las exportaciones haya aumentado a lo largo del período de análisis. observados a lo largo del tiempo, indican la tendencia a exportar más hacia el interior del bloque. El IOR asume la siguiente forma:

donde:

$$
\mathrm{IOR}=(X r j / X t r) /(X o j / X t o)
$$

$X r j=$ valor de las exportaciones brasileñas de automóviles dentro del bloque;

$X t r=$ valor de las exportaciones brasileñas dentro del bloque;

$X o j=$ valor de las exportaciones brasileñas de automóviles fuera del bloque;

$X t o=$ valor de las exportaciones brasileñas fuera del bloque.

El IVCR, originalmente propuesto por Balassa (1965), se basa en el principio de las ventajas comparativas. Con él se busca determinar los productos que un determinado país "a" produce con mayor competitividad en relación con el resto del mundo, basándose para ello en los flujos de comercio pasados de un determinado producto "i" con respecto a la exportación total del país "a", o sea, el porcentaje del producto " $i$ " en la pauta de exportación del país "a", comparado con la exportación total mundial del producto "i” en relación con la exportación total mundial. Si el IVCR es superior a 1, el país tiene una ventaja comparativa revelada en las exportaciones del producto, mientras que si es inferior a 1 el país presenta una desventaja comparativa revelada. Un índice creciente significa un aumento de la competitividad del producto en el país a lo largo del tiempo. El índice se obtiene mediante la siguiente ecuación:

donde:

$$
I V C R \mathrm{j}=(X i j / X i) /(X w j / X w)
$$

$X i j=$ valor de las exportaciones brasileñas de automóviles;

$X i=$ valor de las exportaciones brasileñas;

$X w j=$ valor de las exportaciones mundiales de automóviles; $X w=$ valor de las exportaciones mundiales.

La utilización conjunta de los dos índices permite verificar si después de la formación de un bloque este 
evoluciona de acuerdo con las ventajas comparativas de sus miembros. Si los productos que presentan el mayor dinamismo en el comercio intrabloque (medido a través del IOR) son competitivos, el bloque se especializaría en productos con los cuales es competitivo a nivel internacional. Sin embargo, si los productos que registran el mayor crecimiento del IOR no son competitivos, el bloque podría estar desviando el comercio probablemente en razón de una estructura proteccionista elevada con respecto al resto del mundo. No obstante, cuando se examinan sectores caracterizados por la presencia de economías de escala, es necesario analizar también la evolución del IVCR a lo largo del tiempo, pues la ampliación del mercado derivada de la creación de un bloque puede afectar positivamente a la escala de producción de esos sectores, acrecentando su eficiencia ${ }^{6}$.

6 De acuerdo con Yeats (1997), el IVCR presenta algunos defectos.
Cuando se aplica a los productos agrícolas, el resultado del índice
puede estar distorsionado por tratarse de un sector muy influenciado
por los gobiernos, ya sea mediante incentivos a las exportaciones y
subsidios o por medio de altas barreras arancelarias y no arancelarias.
Además, este índice no capta la influencia de factores cíclicos que
pueden afectar al nivel de exportaciones de los países en determinados
períodos, de modo que a veces puede estar sobrestimado o subestimado.

\section{Resultados y análisis}

En esta sección se evalúan la orientación y la competitividad de las exportaciones del sector automotor brasileño hacia el MERCOSUR entre 1991 y 2010. Como se muestra en el gráfico 3, es posible apreciar tres fases bien distintas ${ }^{7}$. La primera, de 1991 a 1998, está marcada por el fuerte

\footnotetext{
${ }^{7}$ En el artículo solo se analizan las exportaciones brasileñas hacia el bloque, porque estas representan el mayor flujo de comercio bilateral del sector.
}

incremento de las exportaciones brasileñas hacia el bloque, que llegaron al 49\% del total en 1997. Durante la segunda fase, de 1999 a 2002, se registra una acentuada contracción de los flujos comerciales, justificada por la inestabilidad macroeconómica de los principales socios del bloque (desvalorización cambiaria brasileña y crisis argentina), que influiría considerablemente en el sector. Al final del período, en 2002, las exportaciones del sector hacia el bloque habían disminuido a apenas un $8 \%$. La última fase, de 2003 a 2010, se destaca por la reanudación

GRÁFICO 3

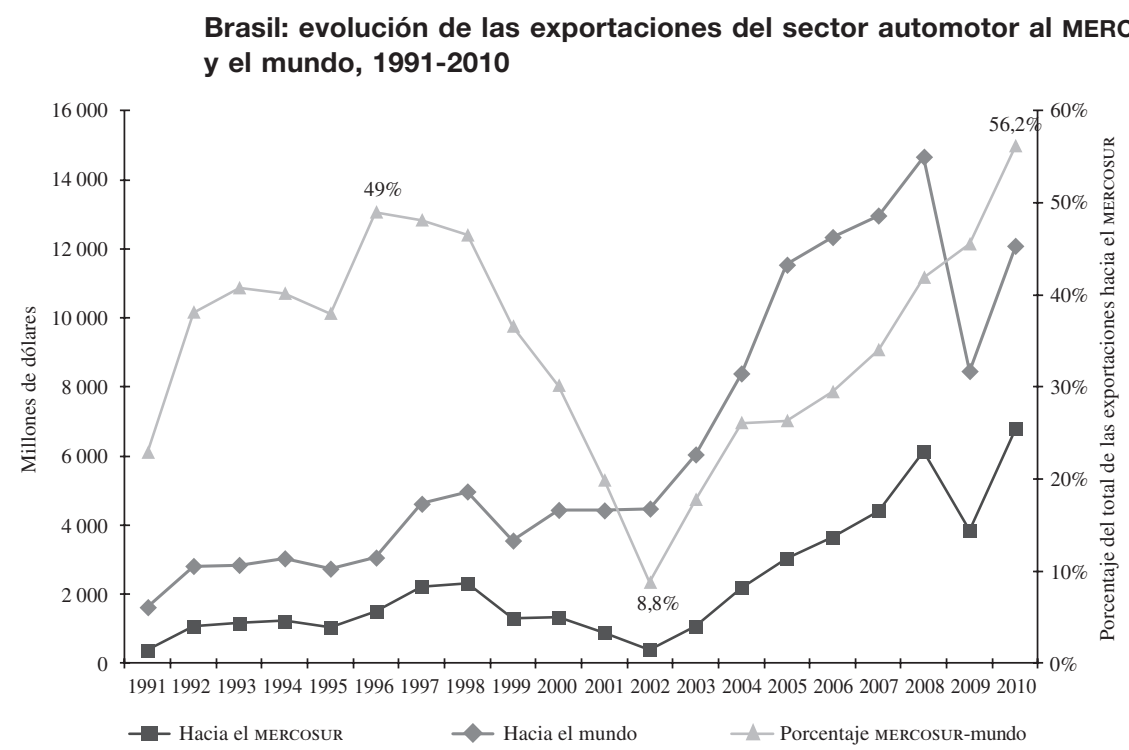

Fuente: Agencia Brasileña de Promoción de Exportaciones e Inversiones (Apex-Brasil).

Mercosur: Mercado Común del Sur. 
del crecimiento de las exportaciones brasileñas hacia el MERCOSUR, cuya participación alcanzó al 56,2\%, el porcentaje más alto de todo el período examinado.

A partir de la metodología descrita en la sección anterior, se examinó en primer lugar el desempeño de las exportaciones hacia el MERCOSUR del sector automotor brasileño en el período de 1991 a 2010. En el cuadro 2 se muestran los 24 productos de dicho sector con códigos de seis dígitos del Sistema Armonizado que presentaron la mayor reorientación de comercio hacia el bloque según el IOR, así como su IVCR ${ }^{8}$. La comparación de estos dos indicadores permite determinar si los productos que presentaron una mayor reorientación de comercio dentro del bloque eran también competitivos ${ }^{9}$. Cabe destacar

${ }^{8}$ Conviene subrayar que, entre 1991 y 2010,39 de los 76 productos de ese capítulo registraron un aumento del IOR Sin embargo, solo 24 alcanzaron también el nivel mínimo de 50.000 dólares establecido para las exportaciones brasileñas hacia el MERCOSUR en 1991.

${ }^{9}$ Diez de estos productos pertenecen al segmento de "partes y accesorios de los vehículos" (Sistema Armonizado 8708) y cuatro a "vehículos automóviles para transporte de mercancías" (Sistema Armonizado 8704). que incluso al inicio de la formación del MERCOSUR, en 1991, el IOR medio de esos productos era superior a 1. En otras palabras, ya había un sesgo de comercio de las exportaciones brasileñas hacia el bloque, que creció aún más desde entonces y pasó de 2,8 a 11,9 entre 1991 y 2010.

Llama la atención que gran parte de los productos que registraron la mayor variación del IOR (ocho) eran competitivos tanto en 1991 como en 2010. Ese último año, más de la mitad de los productos (13) presentaban un IVCR superior a la unidad y constituían el $78 \%$ de las exportaciones brasileñas de este grupo de productos hacia el bloque. $\mathrm{O}$ sea, cuando se tiene en cuenta la relevancia de los productos del sector en el comercio interno del MERCosur, la mayor parte de ellos se consideran competitivos internacionalmente. Por ejemplo, los dos productos que registraron el mayor valor de exportaciones hacia el bloque en 2010, es decir, "los demás vehículos con motor de émbolo (pistón) alternativo, de encendido por chispa de cilindrada superior a $1.500 \mathrm{~cm}^{3}$, pero inferior o igual a $3.000 \mathrm{~cm}^{3}$, para más de seis pasajeros" (Sistema Armonizado 870323) y "los demás vehículos con motor de émbolo (pistón) alternativo, de encendido

CUADRO 2

Índice de orientación regional e índice de ventajas comparativas reveladas, 1991-2010

\begin{tabular}{|c|c|c|c|c|c|c|c|c|c|}
\hline $\begin{array}{l}\text { Sistema } \\
\text { Armonizado } \\
6\end{array}$ & \multicolumn{2}{|c|}{$\begin{array}{c}\text { Exportaciones hacia el } \\
\text { MERCOSUR } \\
\text { (en miles de dólares) }\end{array}$} & \multicolumn{3}{|c|}{ Índice de orientación regional (IOR) } & \multicolumn{3}{|c|}{$\begin{array}{l}\text { Índice de ventajas comparativas } \\
\text { reveladas (IVCR) }\end{array}$} & 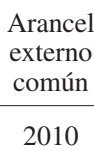 \\
\hline 870333 & 979 & 931 & 436,7 & 738,5 & 301,8 & 0,04 & 0,00 & $-0,03$ & 35 \\
\hline 870421 & 16967 & 411482 & 1,6 & 82,2 & 80,6 & 1,99 & 0,91 & $-1,08$ & 35 \\
\hline 870850 & 4017 & 265597 & 1,5 & 25,5 & 24,1 & 2,49 & 1,61 & $-0,88$ & 14 \\
\hline 870422 & 13835 & 305734 & 2,6 & 23,1 & 20,4 & 1,40 & 1,87 & 0,47 & 35 \\
\hline 870829 & 3117 & 401315 & 2,7 & 15,4 & 12,7 & 0,13 & 0,95 & 0,83 & 18 \\
\hline 870130 & 56 & 313 & 0,2 & 12,1 & 11,9 & 0,41 & 0,03 & $-0,38$ & 14 \\
\hline 870323 & 59002 & 2127537 & 6,9 & 18,6 & 11,6 & 0,17 & 1,06 & 0,89 & 35 \\
\hline 870894 & 2429 & 91891 & 2,1 & 13,7 & 11,6 & 1,22 & 0,79 & $-0,43$ & 18 \\
\hline 870870 & 1960 & 115689 & 0,5 & 10,8 & 10,3 & 2,26 & 1,09 & $-1,16$ & 18 \\
\hline 870891 & 1321 & 40945 & 2,8 & 12,7 & 9,9 & 0,80 & 0,84 & 0,04 & 18 \\
\hline 870880 & 4904 & 117744 & 3,1 & 9,8 & 6,7 & 1,76 & 1,35 & $-0,41$ & 18 \\
\hline 871419 & 59 & 5767 & 0,8 & 7,3 & 6,6 & 0,11 & 0,17 & 0,06 & 16 \\
\hline 870893 & 3145 & 68214 & 1,8 & 6,5 & 4,7 & 1,77 & 1,41 & $-0,36$ & 18 \\
\hline 870810 & 501 & 15803 & 1,7 & 6,1 & 4,4 & 0,26 & 0,51 & 0,24 & 18 \\
\hline 870431 & 24945 & 214821 & 2,8 & 6,7 & 3,8 & 0,80 & 1,71 & 0,91 & 35 \\
\hline 870600 & 5641 & 218081 & 1,1 & 4,1 & 3,1 & 4,71 & 13,24 & 8,53 & 35 \\
\hline 871640 & 653 & 100 & 6,7 & 8,8 & 2,1 & 1,31 & 0,02 & $-1,29$ & 35 \\
\hline 870322 & 57267 & 668818 & 11,3 & 13,0 & 1,7 & 0,41 & 1,27 & 0,86 & 35 \\
\hline 870423 & 1829 & 62248 & 0,6 & 1,8 & 1,3 & 1,32 & 1,99 & 0,68 & 35 \\
\hline 871120 & 2286 & 50561 & 4,6 & 4,9 & 0,4 & 0,59 & 1,46 & 0,87 & 20 \\
\hline 870210 & 6148 & 27139 & 0,7 & 0,8 & 0,1 & 4,96 & 1,99 & $-2,97$ & 35 \\
\hline Total & 225627 & 5795371 & 2,81 & 11,94 & 9,1 & 0,59 & 1,17 & 0,58 & 25,5 \\
\hline
\end{tabular}

Fuente: elaboración propia sobre la base de datos de Agencia Brasileña de Promoción de Exportaciones e Inversiones (Apex-Brasil). MERCOSUR: Mercado Común del Sur. 
por chispa de cilindrada superior a $1.000 \mathrm{~cm}^{3}$ pero inferior o igual a $1.500 \mathrm{~cm}^{3}$, hasta seis pasajeros" (Sistema Armonizado 870322) no solo presentaron un IVCR superior a 1 ese año, sino que este también fue aumentando entre 1991 y 2010. Al tener en cuenta el IVCR agregado de todos los productos con variación positiva de la orientación regional, se observa que este se acrecentó significativamente en el período analizado, pasando de 0,59 en 1991 a 1,17 en 2010.

Por lo tanto, al contrario de las conclusiones de Yeats (1997) con respecto al período 1988-1994, el gran crecimiento del comercio del sector automotor en el ámbito del MERCOSUR entre 1991 y 2010 no parece haberse derivado de un proceso de desviación de comercio. Como se observó, tanto en términos de cantidad de productos como de representatividad de su valor de comercio, la mayoría de los productos con mayor dinamismo en las exportaciones brasileñas hacia el bloque eran o se volvieron competitivos a nivel internacional a lo largo del período examinado.

Asimismo, se registró un incremento del IVCR con respecto a 14 de los 24 productos más dinámicos en el comercio dentro del bloque entre 1991 y 2010, lo que indica que su competitividad se habría acrecentado. Ese fenómeno, caracterizado por el aumento de la competitividad de los productos del sector automotor, puede estar relacionado con lo que Corden (1972) llamó "reducción de costos", según se discutió en la sección III.

$\mathrm{Al}$ dividir el sector en productos finales y en partes y componentes, se observa una diferencia significativa en cuanto a su importancia y evolución. Grandes volúmenes de las exportaciones brasileñas hacia el bloque consisten en productos finales, en particular de las categorías 8703 y 8704 . Solo esos dos grupos de productos representaron casi dos tercios $(65,4 \%)$ de las exportaciones brasileñas hacia el MERCOSUR en 2010. Asimismo, hubo un aumento del IVCR de la mayoría de esos productos a lo largo del período examinado. Si bien numerosos productos del conjunto de partes y componentes, donde se destacan los de la categoría 8708 , registraron un incremento del IOR, ellos representaban apenas un 24,6\% de las exportaciones del sector en 2010. Además de una menor participación en la pauta exportadora sectorial brasileña, el IVCR de la mayor parte de esos productos se contrajo. En ese sentido, dado el menor valor exportado y su pérdida de competitividad, una disminución del proteccionismo con respecto a esos productos podría estimular importaciones a precios más bajos, incrementando aún más la competitividad del sector en los productos finales.

Como se mencionó anteriormente, 14 de los productos examinados mostraron un aumento del IVCR entre 1991 y 2010 y, en consecuencia, podrían ser objeto del análisis. De acuerdo con los criterios establecidos, cinco de ellos pueden caracterizarse como casos de "reducción de costos". Las exportaciones sumadas de esos productos se incrementaron un $2.204 \%$ en el período de referencia, al pasar de 144,8 millones de dólares en 1991 a 3.338 millones de dólares en 2010. Como resultado, solo esos rubros representaron el 57,6\% de las exportaciones de los productos más dinámicos del comercio intrabloque en 2010. Llama la atención que el AEC de cuatro de ellos era del 35\% en 2010, el máximo permitido por el bloque, mientras que el del quinto producto (20\%) superaba también la media. Aparentemente, el elevado proteccionismo con respecto a esos productos puede ser la causa principal del aumento de las exportaciones brasileñas hacia el MERCOSUR. Empero, vistas las economías de escala y el consiguiente incremento de eficiencia, la "reducción de costos" puede haber producido ganancias de bienestar para la población, algo que no ocurriría en caso de desviación de comercio. Los datos relativos a otros seis productos, cuyas exportaciones alcanzaron un valor de 772,2 millones de dólares en 2010 (equivalentes al 13,3\% del total), indicarían casos de "supresión de comercio" 10 . Así, los subsectores del sector automotor brasileño que más acrecentaron sus exportaciones hacia el bloque (alrededor del 70\% del valor exportado por el sector hacia el bloque en 2010) se habrían beneficiado de la existencia de economías de escala, lo que se tradujo en un incremento de su competitividad (medida según el IVCR) a lo largo del período.

En consecuencia, si bien la formación del MERCOSUR podría ser una de las razones de la mayor competitividad de los productos más dinámicos en el comercio intrabloque, no fue suficiente para prescindir de un AEC elevado. En ese sentido, Tigre y otros (1999) examinan con más profundidad el desempeño de la industria automovilística después de la entrada en vigor de la primera versión del Régimen Automotor y argumentan, por ejemplo, que el MERCOSUR cumplió un papel decisivo en la reestructuración del sector, sobre todo en la Argentina y el Brasil. Según los autores, el acuerdo regional permitió que las empresas multinacionales, presentes en los dos países, adoptaran estrategias de especialización regional que incrementaron el comercio de productos finales e insumos intrabloque. El análisis anterior evidenció que ese aumento del comercio parece ser resultado de la mayor eficiencia de

\footnotetext{
${ }^{10}$ Los tres productos restantes (de los 14 mencionados) ya presentaban un IVCR superior a 1 en 1991 y, por lo tanto, no se enmarcan en ninguna de las dos situaciones.
} 
las empresas que operan en el MERCOSUR (sobre todo en el caso de los productos finales), las que se beneficiaron de un mercado ampliado y relativamente protegido para aprovechar las economías de escala características del sector automotor.

Además de analizar el período 1991-2010 en forma global, en este artículo se examina también la evolución del comercio intrabloque y de la competitividad de los productos del sector automotor que más crecieron en ese comercio durante tres subperíodos, que corresponden a cada una de las principales fases del comercio entre los miembros del bloque. Como se demostró en el análisis previo, entre 1991 y 1998 hubo una gran expansión de las exportaciones brasileñas del sector automotor hacia el MERCosur, a raíz de la eliminación preferencial de las elevadas barreras arancelarias vigentes en años anteriores. A medida que se produjo la apertura comercial dentro del bloque, se apreció una marcada tendencia al incremento del comercio entre los países miembros. En el cuadro 3 se detallan los productos con códigos de seis dígitos del Sistema Armonizado cuyo índice de orientación regional
(IOR) registró un aumento absoluto a lo largo de ese período, así como su índice de ventajas comparativas reveladas (IVCR) y su Arancel Externo Común (AEC). El AEC de todos los productos, con excepción de uno, está por sobre el $15 \%$ y en la mayoría de los casos alcanza el límite máximo del 35\%. Estos porcentajes constituyen una de las razones de la acentuada regionalización.

A lo largo del período de referencia se observó una variación positiva del IOR con respecto a 25 productos, con un aumento medio de 1,5 a 6,0. La mayoría de esos productos presentó también un incremento del IVCR, que llegó a 20. Esto muestra una estrecha relación entre el aumento del comercio y el de la competitividad de los productos, que señala una vez más la presencia de economías de escala ligadas a la "reducción de costos". El IVCR medio también creció en forma considerable, al pasar de 1,1 en 1991 a 4,9 en 1998. Así, además de no poder constatarse la preponderancia de productos propensos a la desviación de comercio en el sector, se registró un incremento de la competitividad de la mayor parte de ellos entre 1991 y 1998. En 1998, 12 productos

CUADRO 3

Índice de orientación regional e índice de ventajas comparativas reveladas, 1991-1998

\begin{tabular}{|c|c|c|c|c|c|c|c|c|c|}
\hline $\begin{array}{l}\text { Sistema } \\
\text { Armonizado } \\
6\end{array}$ & \multicolumn{2}{|c|}{$\begin{array}{c}\text { Exportaciones hacia } \\
\text { el MERCOSUR } \\
\text { (en miles de dólares) }\end{array}$} & \multicolumn{3}{|c|}{ Índice de orientación regional (IOR) } & \multicolumn{3}{|c|}{$\begin{array}{l}\text { Índice de ventajas comparativas } \\
\text { reveladas (IVCR) }\end{array}$} & $\begin{array}{c}\begin{array}{c}\text { Arancel } \\
\text { externo } \\
\text { común }\end{array} \\
1998\end{array}$ \\
\hline 871200 & 3165 & 1447 & 20,4 & 177,7 & 157,3 & 0,77 & 0,08 & $-0,69$ & 16 \\
\hline 870422 & 13835 & 310424 & 2,6 & 25,5 & 22,9 & 1,40 & 4,33 & 2,93 & 35 \\
\hline 871620 & 51 & 1764 & 10,1 & 30,0 & 19,9 & 0,13 & 1,16 & 1,03 & 19 \\
\hline 871639 & 433 & 35413 & 3,3 & 13,8 & 10,5 & 0,28 & 1,75 & 1,48 & 35 \\
\hline 870831 & 1056 & 1603 & 2,4 & 12,2 & 9,8 & 0,92 & 0,11 & $-0,80$ & 0 \\
\hline 870829 & 3117 & 95747 & 2,7 & 10,2 & 7,5 & 0,13 & 0,65 & 0,53 & 35 \\
\hline 870421 & 16967 & 279568 & 1,6 & 8,0 & 6,4 & 1,99 & 2,46 & 0,47 & 35 \\
\hline 870892 & 124 & 6164 & 0,6 & 6,5 & 5,9 & 0,20 & 0,48 & 0,28 & 21 \\
\hline 870894 & 2429 & 20135 & 2,1 & 6,0 & 3,9 & 1,22 & 1,09 & $-0,13$ & 21 \\
\hline 871680 & 129 & 813 & 4,1 & 7,4 & 3,3 & 0,15 & 0,25 & 0,10 & 19 \\
\hline 871499 & 958 & 320 & 19,1 & 21,9 & 2,8 & 0,17 & 0,03 & $-0,14$ & 21 \\
\hline 871640 & 653 & 900 & 6,7 & 9,0 & 2,4 & 1,31 & 0,40 & $-0,90$ & 19 \\
\hline 870893 & 3145 & 18433 & 1,8 & 3,6 & 1,8 & 1,77 & 1,85 & 0,08 & 21 \\
\hline 870860 & 1678 & 9482 & 12,7 & 14,3 & 1,6 & 0,24 & 0,61 & 0,37 & 35 \\
\hline 870870 & 1960 & 38326 & 0,5 & 1,9 & 1,4 & 2,26 & 2,54 & 0,29 & 35 \\
\hline 870850 & 4017 & 39652 & 1,5 & 2,9 & 1,4 & 2,49 & 3,44 & 0,95 & 17 \\
\hline 871419 & 59 & 1557 & 0,8 & 2,1 & 1,3 & 0,11 & 0,26 & 0,16 & 35 \\
\hline 870130 & 56 & 1165 & 0,2 & 1,3 & 1,1 & 0,41 & 0,60 & 0,19 & 17 \\
\hline 870839 & 4616 & 44177 & 0,9 & 1,9 & 1,0 & 1,57 & 1,99 & 0,42 & 35 \\
\hline 871690 & 214 & 2371 & 11,1 & 11,9 & 0,8 & 0,04 & 0,14 & 0,10 & 35 \\
\hline 871120 & 2286 & 15479 & 4,6 & 5,0 & 0,5 & 0,59 & 1,31 & 0,72 & 35 \\
\hline 870600 & 5641 & 47639 & 1,1 & 1,4 & 0,4 & 4,71 & 8,56 & 3,85 & 35 \\
\hline 870810 & 501 & 4933 & 1,7 & 2,0 & 0,2 & 0,26 & 0,75 & 0,49 & 35 \\
\hline Total & 67101 & 1091125 & 1,53 & 5,97 & 4,4 & 1,06 & 4,94 & 3,87 & 27,2 \\
\hline
\end{tabular}

Fuente: elaboración propia sobre la base de datos de Agencia Brasileña de Promoción de Exportaciones e Inversiones (Apex-Brasil). MERCOSUR: Mercado Común del Sur. 
presentaban un IVCR superior a $1 \mathrm{y}$ representaban el $80,8 \%$ de las exportaciones brasileñas hacia el bloque de ese grupo. Por lo tanto, al igual que en el período 1991-2010, cuando se tiene en cuenta la importancia de los productos del sector en el comercio intrabloque se observa que este aumentó sobre todo con respecto a productos que ya eran competitivos a nivel internacional o que incrementaron su competitividad.

No obstante la postergación de los acuerdos del régimen automotor, en este período había cierto optimismo con respecto a las perspectivas de crecimiento del comercio dentro del bloque. A pesar de haber diferido algunas veces la plena liberalización del comercio del sector intrabloque, los gobiernos habían dispuesto el libre comercio ( $31^{\circ}$ Protocolo al ACE-14), de modo que las empresas presentes en los dos mayores miembros se beneficiarían de las economías de escala proporcionadas por el proteccionismo regional en muchos productos del sector automotor.

Sin embargo, la inestabilidad macroeconómica causada por crisis externas (México en 1995, Sudeste Asiático en 1997, Federación de Rusia en 1998) o problemas internos (desvalorización cambiaria brasileña en 1999 y moratoria argentina en 2001) interrumpieron la fase más próspera del comercio intrabloque ${ }^{11}$. Los años comprendidos entre

11 Véase un análisis más detallado de los avances y retrocesos del bloque en Preusse (2001).
1999 y 2002 fueron notoriamente el período más crítico para el MERCOSUR, debido a las conmociones provocadas por las crisis financieras internacionales y las consiguientes pérdidas en el flujo comercial regional. En el cuadro 4 se detalla el cálculo de los índices de competitividad y orientación regional en este período, que reflejan las consecuencias del escenario macroeconómico adverso en el sector automotor del Cono Sur.

Se constata que el número de productos que registraron un aumento del IOR es menor en comparación con el período anterior (1991-1998) y que muy pocos de estos eran competitivos, circunstancias que contribuyeron a la retracción del comercio intrabloque. Solo 13 artículos mostraron un incremento del IOR en este segundo período, denotando el menor dinamismo del comercio regional. A su vez, 10 de esos artículos presentaron un IVCR inferior a 1 en 2002. La media de este índice disminuyó de 1,2 a 0,6 en el período de referencia, revelando una pérdida conjunta de competitividad de los productos más dinámicos en el comercio intrabloque. Se destaca una vez más la importancia de la escala de producción, pues las exportaciones brasileñas de los productos con mayor reorientación de comercio hacia el bloque se redujeron en términos absolutos y las exportaciones totales disminuyeron de 366,5 millones de dólares en 1999 a 164,3 millones de dólares en 2002.

En consecuencia, la reorientación de comercio que tuvo lugar se habría debido en gran medida al proteccionismo. El AEC de 12 de los 13 productos

CUADRO 4

Índice de orientación regional e índice de ventajas comparativas reveladas, 1999-2002

\begin{tabular}{|c|c|c|c|c|c|c|c|c|c|}
\hline \multirow{2}{*}{$\begin{array}{l}\text { Sistema } \\
\text { Armonizado } \\
6\end{array}$} & \multicolumn{2}{|c|}{$\begin{array}{c}\text { Exportaciones hacia el } \\
\text { MERCOSUR } \\
\text { (en miles de dólares) }\end{array}$} & \multicolumn{3}{|c|}{ Índice de orientación regional (IOR) } & \multicolumn{3}{|c|}{$\begin{array}{c}\text { Índice de ventajas comparativas } \\
\text { reveladas (IVCR) }\end{array}$} & \multirow{2}{*}{ 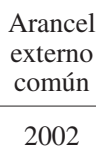 } \\
\hline & 1999 & 2002 & 1999 & 2002 & Variación & 1999 & 2002 & Variación & \\
\hline 871494 & 51 & 8 & 159,5 & 184,1 & 24,6 & 0,02 & 0,00 & $-0,02$ & 16 \\
\hline 870540 & 272 & 269 & 2,1 & 7,6 & 5,5 & 0,55 & 0,30 & $-0,25$ & 35 \\
\hline 870421 & 110487 & 49601 & 3,6 & 9,0 & 5,4 & 2,01 & 0,74 & $-1,27$ & 16 \\
\hline 870840 & 35243 & 27760 & 1,9 & 5,5 & 3,6 & 1,10 & 0,69 & $-0,41$ & 35 \\
\hline 870332 & 86755 & 29681 & 2,5 & 3,9 & 1,4 & 0,80 & 0,28 & $-0,51$ & 18 \\
\hline 870810 & 4510 & 1140 & 2,0 & 3,2 & 1,2 & 0,92 & 0,30 & $-0,61$ & 14 \\
\hline 871492 & 144 & 22 & 3,0 & 4,0 & 1,0 & 0,25 & 0,06 & $-0,19$ & 35 \\
\hline 870850 & 34712 & 12098 & 3,0 & 3,8 & 0,8 & 3,87 & 2,37 & $-1,49$ & 18 \\
\hline 870322 & 67821 & 19781 & 1,7 & 2,5 & 0,8 & 1,30 & 0,57 & $-0,73$ & 20 \\
\hline 870892 & 3405 & 2014 & 6,9 & 7,6 & 0,6 & 0,31 & 0,23 & $-0,08$ & 16 \\
\hline 870880 & 9197 & 3462 & 1,2 & 1,5 & 0,3 & 2,88 & 1,73 & $-1,16$ & 35 \\
\hline 870190 & 13760 & 18394 & 2,2 & 2,5 & 0,3 & 0,82 & 1,92 & 1,10 & 18 \\
\hline 870590 & 148 & 140 & 0,5 & 0,5 & 0,0 & 0,12 & 0,24 & 0,12 & 18 \\
\hline Total & 366506 & 164369 & 2,42 & 4,12 & 1,7 & 1,21 & 0,60 & $-0,61$ & 22,6 \\
\hline
\end{tabular}

Fuente: elaboración propia sobre la base de datos de Agencia Brasileña de Promoción de Exportaciones e Inversiones (Apex-Brasil). MERCosur: Mercado Común del Sur. 
examinados era superior al $15 \%$ y llegaba al $35 \%$ en buena parte de los casos. Además, solo cuatro de los productos con mayor reorientación de comercio figuraban entre los más dinámicos en el período 1991-1998, lo que revela una alteración profunda en la pauta de exportación brasileña hacia el bloque en ese período de crisis.

Cabe destacar que, a partir de junio de 2000, entró en vigor el comercio administrado entre los países del MERCOSUR, caracterizado por el sistema del flex. Asimismo, también en esta fase de integración y debido a la crisis que estaba atravesando, el mercado argentino no pudo absorber más los productos fabricados por su propia industria y aumentó sus exportaciones al Brasil, incluso más allá del flex, generando un comercio tributado, conforme a lo previsto por las reglas establecidas.

Una vez pasada la peor fase de la crisis, la recuperación del comercio intrabloque benefició también al sector automotor. Como se muestra en el cuadro 5, en el período 2003-2010 se registró un crecimiento del IOR de 36 productos del sector automotor con códigos de seis dígitos del Sistema Armonizado. Cuatro de esos productos registraron una variación absoluta del índice superior a 100. Mientras que el IOR medio de estos creció en forma significativa, pasando de 2,3 en 2003 a 10,9

CUADRO 5

Índice de orientación regional e índice de ventajas comparativas reveladas, 2003-2010

\begin{tabular}{|c|c|c|c|c|c|c|c|c|c|}
\hline \multirow{2}{*}{$\begin{array}{l}\text { Sistema } \\
\text { Armonizado } \\
6\end{array}$} & \multicolumn{2}{|c|}{$\begin{array}{c}\text { Exportaciones hacia el } \\
\text { MERCOSUR } \\
\text { (en miles de dólares) }\end{array}$} & \multicolumn{3}{|c|}{ Índice de orientación regional (IOR) } & \multicolumn{3}{|c|}{$\begin{array}{c}\text { Índice de ventajas comparativas } \\
\text { reveladas (IVCR) }\end{array}$} & \multirow{2}{*}{$\begin{array}{c}\begin{array}{c}\text { Arancel } \\
\text { externo } \\
\text { común }\end{array} \\
2010\end{array}$} \\
\hline & 2003 & 2010 & 2003 & 2010 & Variación & 2003 & 2010 & Variación & \\
\hline 870120 & 42303 & 276281 & 4,2 & 9,1 & 4,9 & 1,21 & 1,90 & 0,68 & 35 \\
\hline 870210 & 2011 & 27139 & 0,2 & 0,8 & 0,6 & 1,88 & 1,99 & 0,11 & 35 \\
\hline 870321 & 18892 & 72707 & 14,0 & 187,4 & 173,4 & 0,54 & 0,50 & $-0,03$ & 35 \\
\hline 870322 & 73296 & 668818 & 7,3 & 13,0 & 5,7 & 0,58 & 1,27 & 0,69 & 35 \\
\hline 870323 & 262516 & 2127537 & 1,6 & 18,6 & 17,0 & 1,39 & 1,06 & $-0,33$ & 35 \\
\hline 870331 & 23760 & 65872 & 36,6 & 46,0 & 9,4 & 0,49 & 0,29 & $-0,20$ & 35 \\
\hline 870333 & 7842 & 931 & 60,4 & 738,5 & 678,1 & 0,06 & 0,00 & $-0,06$ & 35 \\
\hline 870410 & 235 & 513 & 0,1 & 0,2 & 0,1 & 1,89 & 0,28 & $-1,62$ & 14 \\
\hline 870421 & 128669 & 411482 & 14,0 & 82,2 & 68,2 & 1,00 & 0,91 & $-0,08$ & 35 \\
\hline 870422 & 64601 & 305734 & 16,1 & 23,1 & 6,9 & 1,03 & 1,87 & 0,84 & 35 \\
\hline 870423 & 4650 & 62248 & 0,4 & 1,8 & 1,5 & 2,04 & 1,99 & $-0,05$ & 35 \\
\hline 870600 & 20720 & 218081 & 1,0 & 4,1 & 3,2 & 12,01 & 13,24 & 1,23 & 35 \\
\hline 870710 & 56 & 33 & 0,2 & 1,1 & 0,9 & 0,28 & 0,01 & $-0,28$ & 35 \\
\hline 870790 & 10994 & 69288 & 0,8 & 2,3 & 1,5 & 6,45 & 6,29 & $-0,16$ & 35 \\
\hline 870810 & 1569 & 15803 & 1,6 & 6,1 & 4,5 & 0,42 & 0,51 & 0,09 & 18 \\
\hline 870821 & 1132 & 36876 & 10,6 & 117,7 & 107,1 & 0,09 & 1,09 & 1,00 & 18 \\
\hline 870829 & 34291 & 401315 & 4,1 & 15,4 & 11,3 & 0,39 & 0,95 & 0,56 & 14 \\
\hline 870840 & 27639 & 289995 & 3,4 & 12,1 & 8,7 & 0,63 & 0,83 & 0,20 & 18 \\
\hline 870850 & 19197 & 265597 & 4,3 & 25,5 & 21,3 & 2,49 & 1,61 & $-0,88$ & 14 \\
\hline 870870 & 14129 & 115689 & 1,3 & 10,8 & 9,5 & 1,86 & 1,09 & $-0,76$ & 14 \\
\hline 870880 & 5436 & 117744 & 1,4 & 9,8 & 8,4 & 1,55 & 1,35 & $-0,20$ & 18 \\
\hline 870891 & 4397 & 40945 & 1,6 & 12,7 & 11,1 & 1,33 & 0,84 & $-0,49$ & 18 \\
\hline 870892 & 707 & 18365 & 2,2 & 22,8 & 20,7 & 0,14 & 0,28 & 0,14 & 18 \\
\hline 870893 & 7066 & 68214 & 2,4 & 6,5 & 4,0 & 1,16 & 1,41 & 0,24 & 18 \\
\hline 870894 & 4544 & 91891 & 3,3 & 13,7 & 10,4 & 0,40 & 0,79 & 0,39 & 18 \\
\hline 870899 & 61882 & 268284 & 1,3 & 4,6 & 3,3 & 0,98 & 0,63 & $-0,36$ & 18 \\
\hline 871120 & 5193 & 50561 & 0,5 & 4,9 & 4,5 & 4,33 & 1,46 & $-2,87$ & 20 \\
\hline 871491 & 80 & 109 & 9,2 & 26,7 & 17,5 & 0,03 & 0,01 & $-0,02$ & 16 \\
\hline 871495 & 1187 & 707 & 45,0 & 166,2 & 121,2 & 1,08 & 0,22 & $-0,86$ & 16 \\
\hline 871496 & 691 & 568 & 249,2 & 300,5 & 51,3 & 0,26 & 0,06 & $-0,20$ & 16 \\
\hline 871500 & 77 & 21 & 1,0 & 19,0 & 18,0 & 0,11 & 0,00 & $-0,11$ & 20 \\
\hline 871640 & 201 & 100 & 4,5 & 8,8 & 4,3 & 0,16 & 0,02 & $-0,15$ & 35 \\
\hline 871690 & 786 & 13589 & 1,8 & 9,4 & 7,6 & 0,19 & 0,37 & 0,18 & 16 \\
\hline Total & 859740 & 6328535 & 2,29 & 10,90 & 8,6 & 1,12 & 1,08 & $-0,04$ & 24,4 \\
\hline
\end{tabular}

Fuente: elaboración propia sobre la base de datos de Agencia Brasileña de Promoción de Exportaciones e Inversiones (Apex-Brasil). MERCOSUR: Mercado Común del Sur. 
en 2010; el IVCR medio se mantuvo estable, alrededor de 1,1. Gran parte de esos productos (16) registraron un incremento del IVCR y todos ellos presentaron un marcado aumento del valor exportado hacia el bloque en el período analizado. Esto indica una estrecha relación entre el crecimiento del comercio y de la competitividad de los productos, que a su vez señala el aprovechamiento de las economías de escala. Tres productos mostraron señales de "reducción de costos" y ocho de "supresión de comercio". Los demás productos eran competitivos en 2003 y su IVCR se había acrecentado aún más en 2010. Así, además de no poder constatarse la preponderancia de productos propensos a la desviación de comercio en el sector, se registró un incremento de la competitividad de la mayor parte de ellos entre 2003 y 2010.

En resumen, con la metodología aplicada se mostró que en ninguno de los períodos en que hubo expansión del comercio se apreciaron señales evidentes del predominio de la desviación de comercio, pero sí de ganancias ligadas al aprovechamiento de las economías de escala, especialmente en los sectores más protegidos. En otras palabras, a lo largo del período analizado aumentó la competitividad de gran parte de los productos del sector automotor, posiblemente debido a las economías de escala (caracterizadas por el incremento del IVCR). Esto configuraría una situación de "reducción de costos" o de "supresión de comercio", en conformidad con los conceptos establecidos por Corden (1972) para estudiar los efectos de la formación de bloques de países en productos sujetos a economías de escala. Ese desempeño intrabloque se explica parcialmente porque el AEC de esos productos es superior a la media. En otras palabras, las elevadas preferencias del sector automotor parecen ser las principales responsables de la reorientación de comercio que tuvo lugar respecto de los productos del sector a partir de la formación del MERCOSUR. Sin embargo, debido a las ganancias de eficiencia observadas en los productos con mayor reorientación de comercio hacia el bloque, hay señales de ganancias de bienestar para la población de este que contradicen el análisis de Yeats (1997). Ese autor estableció la presencia de desviación de comercio en relación con gran parte de los productos cuyo comercio intrabloque aumentó, incluido el sector automotor.

\section{VI}

\section{Consideraciones finales}

La implementación del arancel externo común (AEC) en 1995, basada en la Nomenclatura Común del MERCosur (NCM), constituyó un gran paso hacia una política comercial común entre los países miembros del bloque. Sin embargo, hubo un incremento del grado de proteccionismo de muchos productos con respecto a la situación anterior, en particular en el sector automotor. En varios estudios (por ejemplo, Kume y Piani, 2005) se evidencia el alto grado de proteccionismo del sector automotor, medido tanto a partir de los aranceles nominales de importación como de los aranceles efectivos. En realidad, a través del AEC, este sector se configura como el más protegido del MERCOSUR. Dado ese alto nivel de proteccionismo del sector con respecto a los países extrabloque, surge la posibilidad de que el comercio intrabloque crezca incluso con respecto a productos no competitivos, causando temores de desviación de comercio.

Sin embargo, cuando se incorpora la posibilidad de economías de escala, la formación del bloque podría ser una de las razones de la mayor competitividad de los productos más dinámicos del sector automotor en el comercio interno, aunque aún insuficiente para prescindir de un AEC elevado. El análisis, basado en los índices IOR y IVCR, mostró que ese incremento del comercio parece derivarse de una mayor eficiencia de las empresas que operan en el bloque, las que se beneficiarían de un mercado ampliado y relativamente protegido para aprovechar las economías de escala, características del sector automotor.

Por lo tanto, al examinar las exportaciones brasileñas hacia el bloque se observa que gran parte de esos productos parecen haber sufrido en realidad una "reducción de costos" o una "supresión de comercio", conceptos acuñados por Corden (1972) para establecer los efectos de los bloques en los sectores en que hay economías de escala. Si bien es cierto que el dinamismo de las exportaciones brasileñas al MERCOSUR se explica en parte por un AEC superior a la media, el sector automotor ya estaba protegido antes de la formación del bloque. A pesar de que las elevadas preferencias del sector parecen ser las principales responsables de la reorientación regional del comercio de sus productos 
a partir de la formación del MERCOSUR, la existencia de economías de escala indica la posibilidad real de ganancias de bienestar.

De este modo, debido a las economías de escala obtenidas con la expansión de las exportaciones de la industria automotriz se sugiere una intensificación del proceso de progresividad arancelaria ya existente en el sector. En consecuencia, se mantendría un elevado grado de protección para los productos finales, en particular los de las categorías 8703 y 8704 . Solo esos dos grupos de productos representaron el $65,4 \%$ de las exportaciones brasileñas del sector automotor hacia el bloque en 2010. En el caso de las partes y componentes, sobre todo los productos de la categoría 8708 , se podría permitir una reducción de los aranceles de importación, que estimularía importaciones a precios más bajos e incrementaría aún más la competitividad del sector en los productos finales. En conclusión, sería oportuno no solo mantener, sino intensificar el proceso de progresividad arancelaria en el sector automotor del MERCOSUR. 
ANEXO

Descripción de los productos del Capítulo 87 de la Nomenclatura Común del MERCOSUR

CAPÍTULO 87

\begin{tabular}{|c|c|}
\hline 87.01 & TRACTORES (EXCEPTO LAS CARRETILLAS TRACTOR DE LA PARTIDA Nº 87.09). \\
\hline 8701.10 .00 & -Motocultores \\
\hline 8701.20 .00 & -Tractores de carretera para semirremolques \\
\hline 8701.30 .00 & -Tractores de orugas \\
\hline 8701.90 .00 & -Los demás \\
\hline 87.02 & $\begin{array}{l}\text { VEHÍCULOS AUTOMÓVILES PARA EL TRANSPORTE DE DIEZ O MÁS PERSONAS, INCLUIDO EL } \\
\text { CONDUCTOR. }\end{array}$ \\
\hline 8702.10 .00 & -Con motor de émbolo (pistón), de encendido por compresión (Diésel o semi Diésel) \\
\hline 8702.90 & -Los demás \\
\hline 8702.90 .10 & Trolebuses \\
\hline 8702.90 .90 & Los demás \\
\hline 87.03 & $\begin{array}{l}\text { COCHES DE TURISMO Y DEMÁS VEHÍCULOS AUTOMÓVILES CONCEBIDOS PRINCIPALMENTE PARA } \\
\text { TRANSPORTE DE PERSONAS (EXCEPTO LOS DE LA PARTIDA N 87.02), INCLUIDOS LOS VEHÍCULOS } \\
\text { DEL TIPO FAMILIAR (“BREAK" O “STATION WAGON") Y LOS DE CARRERAS. }\end{array}$ \\
\hline \multirow[t]{2}{*}{8703.10 .00} & $\begin{array}{l}\text {-Vehículos especialmente concebidos para desplazarse sobre nieve; vehículos especiales para transporte de personas en } \\
\text { campos de golf y vehículos similares }\end{array}$ \\
\hline & -Los demás vehículos con motor de émbolo (pistón) alternativo, de encendido por chispa: \\
\hline 8703.21 .00 & -De cilindrada inferior o igual a $1.000 \mathrm{~cm}^{3}$ \\
\hline 8703.22 & -De cilindrada superior a $1.000 \mathrm{~cm}^{3}$ pero inferior o igual a $1.500 \mathrm{~cm}^{3}$ \\
\hline 8703.22 .10 & Con capacidad de transporte de personas sentadas inferior o igual a 6 , incluido el conductor \\
\hline 8703.22 .90 & Los demás \\
\hline 8703.23 & -De cilindrada superior a $1.500 \mathrm{~cm}^{3}$ pero inferior o igual a $3.000 \mathrm{~cm}^{3}$ \\
\hline 8703.23 .10 & Con capacidad de transporte de personas sentadas inferior o igual a 6 , incluido el conductor \\
\hline 8703.23 .90 & Los demás \\
\hline 8703.24 & -De cilindrada superior a $3.000 \mathrm{~cm}^{3}$ \\
\hline 8703.24 .10 & Con capacidad de transporte de personas sentadas inferior o igual a 6 , incluido el conductor \\
\hline \multirow[t]{2}{*}{8703.24 .90} & Los demás \\
\hline & -Los demás vehículos con motor de émbolo (pistón), de encendido por compresión (Diésel o semi Diésel): \\
\hline 8703.31 & -De cilindrada inferior o igual a $1.500 \mathrm{~cm}^{3}$ \\
\hline 8703.31 .10 & Con capacidad de transporte de personas sentadas inferior o igual a 6 , incluido el conductor \\
\hline 8703.31 .90 & Los demás \\
\hline 8703.32 & -De cilindrada superior a $1.500 \mathrm{~cm}^{3}$ pero inferior o igual a $2.500 \mathrm{~cm}^{3}$ \\
\hline 8703.32 .10 & Con capacidad de transporte de personas sentadas inferior o igual a 6 , incluido el conductor \\
\hline 8703.32 .90 & Los demás \\
\hline 8703.33 & -De cilindrada superior a $2.500 \mathrm{~cm}^{3}$ \\
\hline 8703.33 .10 & Con capacidad de transporte de personas sentadas inferior o igual a 6 , incluido el conductor \\
\hline 8703.33 .90 & Los demás \\
\hline 8703.90 .00 & -Los demás \\
\hline 87.04 & VEHÍCULOS AUTOMÓVILES PARA EL TRANSPORTE DE MERCANCÍAS. \\
\hline \multirow[t]{2}{*}{8704.10 .00} & -Volquetes automotores concebidos para utilizarlos fuera de la red de carreteras \\
\hline & -Los demás, con motor de émbolo (pistón), de encendido por compresión (Diésel o semi Diésel): \\
\hline 8704.21 & -De peso total con carga máxima inferior o igual a $5 \mathrm{t}$ \\
\hline 8704.21 .10 & Chasis con motor y cabina \\
\hline
\end{tabular}




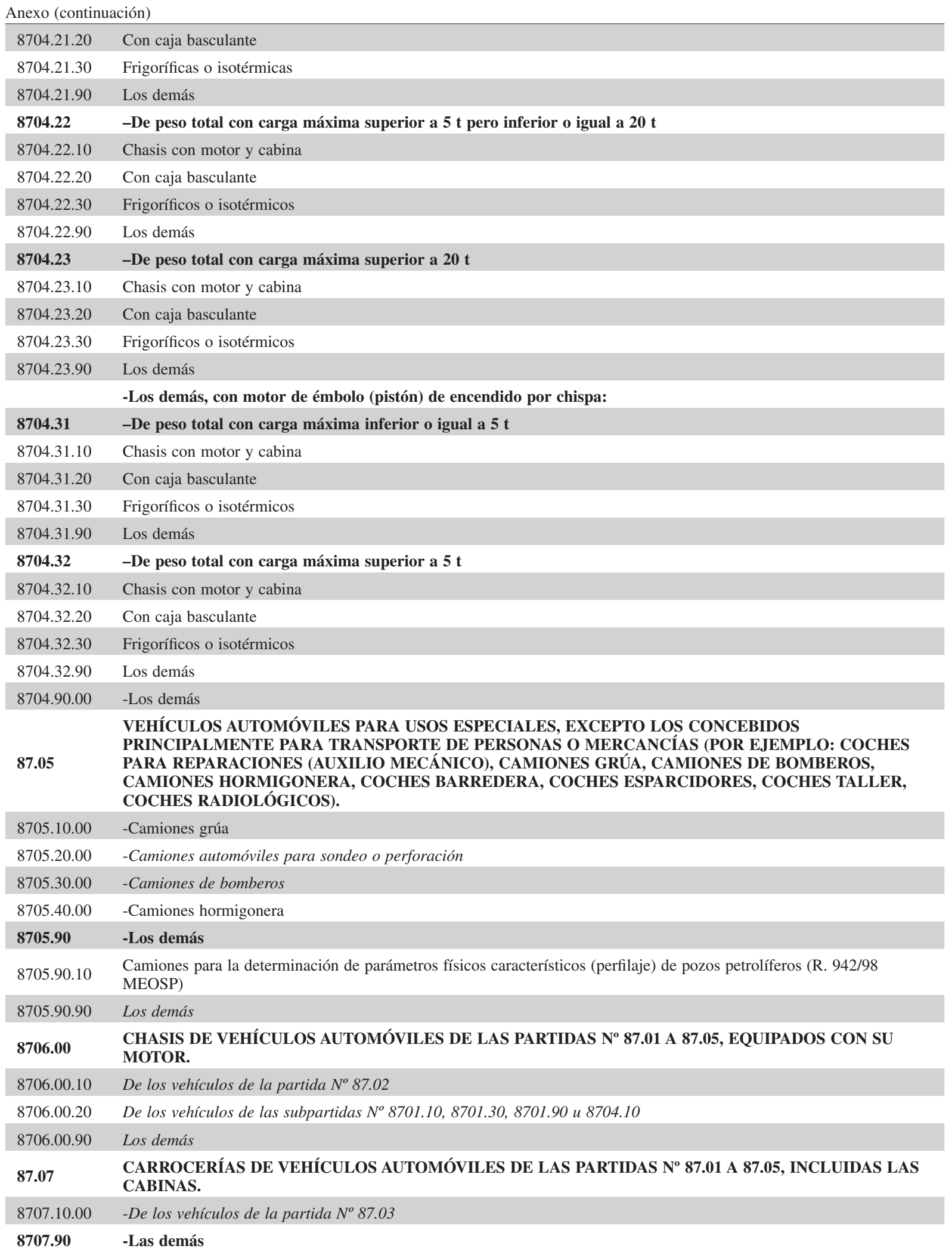




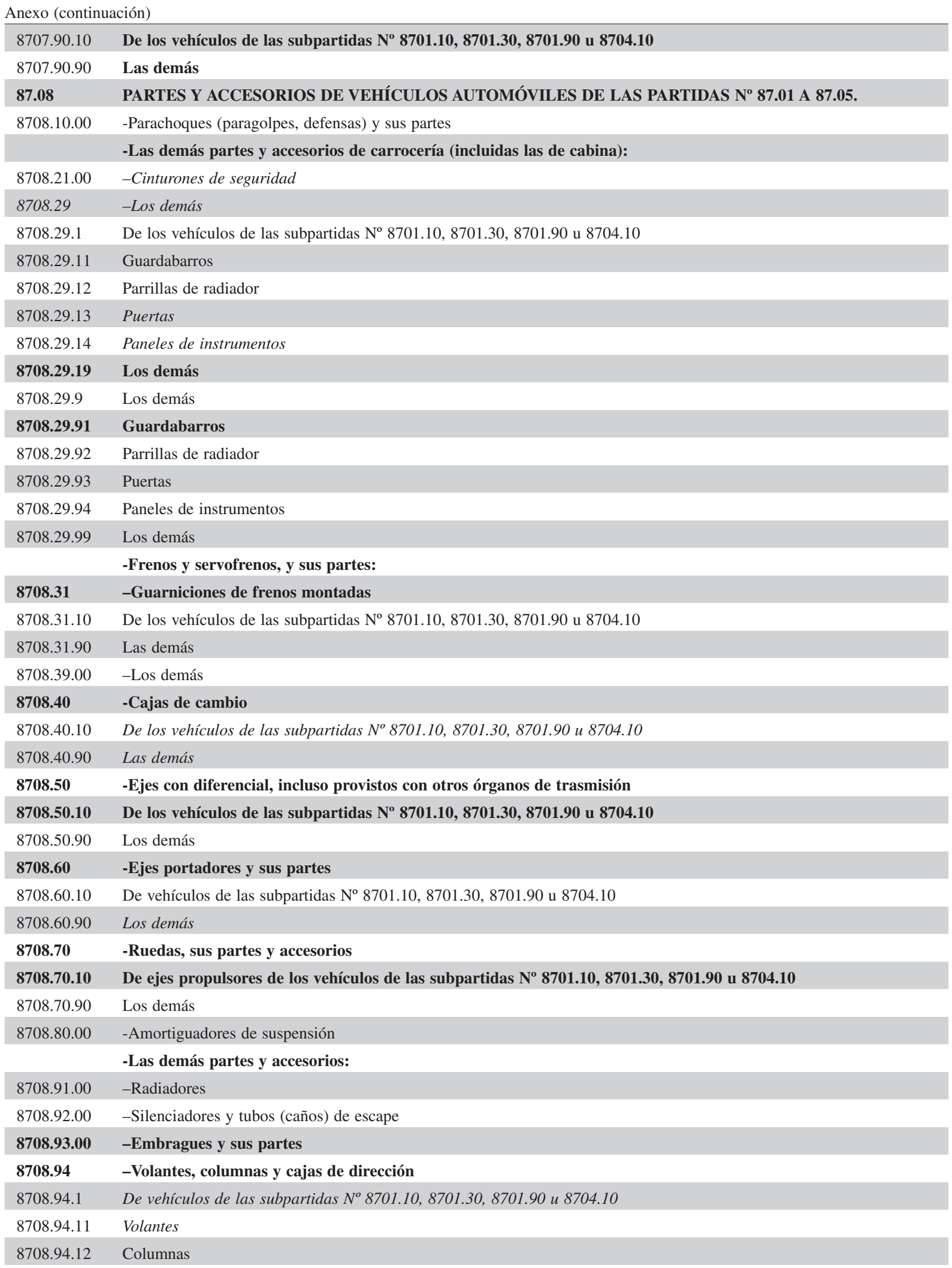




\begin{tabular}{|c|c|}
\hline \multicolumn{2}{|c|}{ Anexo (continuación) } \\
\hline 8708.94.13 & Cajas \\
\hline 8708.94 .9 & Los demás \\
\hline 8708.94 .91 & Volantes \\
\hline 8708.94 .92 & Columnas \\
\hline 8708.94 .93 & Cajas \\
\hline 8708.99 & -Los demás \\
\hline 8708.99 .10 & $\begin{array}{l}\text { Dispositivos para comando de acelerador, freno, embrague, dirección o caja de cambios, incluso los de adaptación de los } \\
\text { preexistentes del tipo de los utilizados por personas discapacitadas (R.1497/98 MEOSP) }\end{array}$ \\
\hline \multirow[t]{2}{*}{87.09} & $\begin{array}{l}\text { CARRETILLAS AUTOMÓVIL SIN DISPOSITIVO DE ELEVACIÓN DEL TIPO DE LAS UTILIZADAS } \\
\text { EN FÁBRICAS, ALMACENES, PUERTOS O AEROPUERTOS, PARA TRANSPORTE DE MERCANCÍAS } \\
\text { A CORTA DISTANCIA; CARRETILLAS TRACTOR DEL TIPO DE LAS UTILIZADAS EN ESTACIONES } \\
\text { FERROVIARIAS; SUS PARTES. }\end{array}$ \\
\hline & -Carretillas: \\
\hline 8709.11 .00 & -Eléctricas \\
\hline 8709.19 .00 & -Las demás \\
\hline 8709.90 .00 & -Partes \\
\hline 8710.00 .00 & $\begin{array}{l}\text { TANQUES Y DEMÁS VEHÍCULOS AUTOMÓVILES BLINDADOS DE COMBATE, INCLUSO CON } \\
\text { ARMAMENTO INCORPORADO; SUS PARTES. }\end{array}$ \\
\hline 87.11 & $\begin{array}{l}\text { MOTOCICLETAS Y TRICICLOS A MOTOR (INCLUIDOS LOS TAMBIÉN A PEDALES) Y VELOCÍPEDOS } \\
\text { EQUIPADOS CON MOTOR AUXILIAR, CON SIDECAR O SIN ÉL; SIDECARES. }\end{array}$ \\
\hline 8711.10 .00 & -Con motor de émbolo (pistón) alternativo de cilindrada inferior o igual a $50 \mathrm{~cm}^{3}$ \\
\hline 8711.20 & -Con motor de émbolo (pistón) alternativo de cilindrada superior a $50 \mathrm{~cm}^{3}$ pero inferior o igual a $250 \mathrm{~cm}^{3}$ \\
\hline 8711.20 .10 & Motocicletas de cilindrada inferior o igual a $125 \mathrm{~cm}^{3}$ \\
\hline 8711.20 .20 & Motocicletas de cilindrada superior a $125 \mathrm{~cm}^{3}$ \\
\hline 8711.20 .90 & Los demás \\
\hline 8711.30 .00 & -Con motor de émbolo (pistón) alternativo de cilindrada superior a $250 \mathrm{~cm}^{3}$ pero inferior o igual a $500 \mathrm{~cm}^{3}$ \\
\hline 8711.40 .00 & -Con motor de émbolo (pistón) alternativo de cilindrada superior a $500 \mathrm{~cm}^{3}$ pero inferior o igual a $800 \mathrm{~cm}^{3}$ \\
\hline 8711.50 .00 & -Con motor de émbolo (pistón) alternativo de cilindrada superior a $800 \mathrm{~cm}^{3}$ \\
\hline 8711.90 .00 & -Los demás \\
\hline 8712.00 & BICICLETAS Y DEMÁS VELOCÍPEDOS (INCLUIDOS LOS TRICICLOS DE REPARTO), SIN MOTOR. \\
\hline 8712.00.10 & Bicicletas \\
\hline 8712.00 .90 & Los demás \\
\hline 87.13 & $\begin{array}{l}\text { SILLONES DE RUEDAS Y DEMÁS VEHÍCULOS PARA INVÁLIDOS, INCLUSO CON MOTOR U OTRO } \\
\text { MECANISMO DE PROPULSIÓN. }\end{array}$ \\
\hline 8713.10 .00 & -Sin mecanismo de propulsión \\
\hline 8713.90.00 & -Los demás \\
\hline \multirow[t]{2}{*}{87.14} & PARTES Y ACCESORIOS DE VEHÍCULOS DE LAS PARTIDAS No 87.11 A 87.13. \\
\hline & -De motocicletas y triciclos a motor (incluidos los también a pedales): \\
\hline 8714.11 .00 & -Sillines (asientos) \\
\hline 8714.19 .00 & -Los demás \\
\hline \multirow[t]{2}{*}{8714.20 .00} & -De sillones de ruedas y demás vehículos para inválidos \\
\hline & -Los demás: \\
\hline 8714.91 .00 & -Cuadros y horquillas, y sus partes \\
\hline 8714.92 .00 & -Llantas y radios \\
\hline 8714.93 .00 & -Bujes sin freno y piñones libres \\
\hline 8714.94 & -Frenos, incluidos los bujes con freno, y sus partes \\
\hline 8714.94 .10 & Bujes con frenos \\
\hline
\end{tabular}




\begin{tabular}{|ll}
\hline Anexo (conclusión) \\
\hline 8714.94 .90 & Los demás \\
\hline 8714.95 .00 & -Sillines (asientos) \\
\hline 8714.96 .00 & -Pedales y mecanismos de pedal, y sus partes \\
\hline 8714.99 .00 & -Los demás \\
\hline $\mathbf{8 7 1 5 . 0 0 . 0 0}$ & COCHES, SILLAS Y VEHÍCULOS SIMILARES PARA TRANSPORTE DE NIÑOS, Y SUS PARTES. \\
\hline $\mathbf{8 7 . 1 6}$ & REMOLQUES Y SEMIRREMOLQUES PARA CUALQUIER VEHÍCULO; LOS DEMÁS VEHÍCULOS NO \\
\hline 8716.10 .00 & -Remolques y semirremolques para vivienda o acampar, del tipo caravana \\
\hline 8716.20 .00 & -Remolques y semirremolques, autocargadores o autodescargadores, para uso agrícola \\
\hline & -Los demás remolques y semirremolques para transporte de mercancías: \\
\hline 8716.31 .00 & -Cisternas \\
\hline 8716.39 .00 & -Los demás \\
\hline $\mathbf{8 7 1 6 . 4 0 . 0 0}$ & -Los demás remolques y semirremolques \\
\hline 8716.80 .00 & -Los demás vehículos \\
\hline $\mathbf{8 7 1 6 . 9 0}$ & -Partes \\
\hline $\mathbf{8 7 1 6 . 9 0 . 1 0}$ & Chasis de remolques y semirremolques \\
\hline 8716.90 .90 & Las demás \\
\hline
\end{tabular}

Fuente: Nomenclatura Común del MERCosur. 


\section{Bibliografía}

Balassa, B. (1965), "Trade liberalization and 'revealed' comparative advantage", The Manchester School of Economic and Social Studies, vol. 33, $\mathrm{N}^{\circ} 2$.

Bhagwati, J. (1993), "Regionalism and multilateralism: an overview", New Dimensions in Regional Integration, J. De Melo y A. Panagariya (eds.), Nueva York, Cambridge University Press.

BID (Banco Interamericano de Desarrollo) (1996), Informe Mercosur, $\mathrm{N}^{\circ}$ 1, Buenos Aires [en línea] http://www.iadb.org/intal/.

(2008), Informe MERCOSUL, $\mathrm{N}^{\circ} 1 / 12$, Buenos Aires [en línea] http://www.iadb.org/intal/.

Casotti, B.P. y M. Goldenstein (2008), "Panorama do setor automotivo: as mudanças estruturais da indústria e as perspectivas para o Brasil”, BNDES Setorial, $\mathrm{N}^{\circ}$ 28, Río de Janeiro, Banco de Desarrollo del Brasil (BNDES).

Corden, W.M. (1972), "Economies of scale and customs union theory", Journal of Political Economy, vol. 80, № 3, Chicago, The University of Chicago Press.

Gabriel, L.F. y otros (2011), "Uma análise da indústria automobilística no Brasil e a demanda de veículos automotores: algumas evidências para o período recente", Anais do $39^{\circ}$ Encontro Nacional de Economia, Río de Janeiro, Asociación Nacional de Centros de Posgrado en Economía (ANPEC).

Giordano, P. y J. Santiso (1999), "La course aux Amériques. Les stratégies des investisseurs européens en Argentine et au Brésil”, Études du CERI, $\mathrm{N}^{\circ}$ 52, París, Centro de Investigación e Innovación en la Enseñanza (CERI).

Kume, H. y G. Piani (2005), "Mercosul: o dilema entre união aduaneira e área de livre-comércio", Revista de Economia Política, vol. 25, $\mathrm{N}^{\circ}$ 4, São Paulo.

Machado, J.B. y M.A. Cavalcanti (1999), "Determinantes do comércio bilateral Argentina-Brasil: uma avaliação dos impactos estáticos do processo de integração no MERCOSUL", XXVII Encontro Nacional de Economia, Río de Janeiro, Asociación Nacional de Centros de Posgrado en Economía (ANPEC).
Negri, J.A. (1999), "O custo do bem-estar do regime automotivo brasileiro", Pesquisa e Planejamento Econômico, vol. 29, $\mathrm{N}^{\circ} 2$, Instituto de Investigación Económica Aplicada (IPEA).

Panagariya, A. (1999), "The regionalism debate: an overview", World Economy, vol. 22, $\mathrm{N}^{\circ} 4$, Wiley.

Piani, G. (1998), "Medidas antidumping, anti-subsídios e de salvaguardas: experiência recente e perspectivas no MERCOSUL", Texto para Discussão, $\mathrm{N}^{\circ} 541$ [en línea] www.ipea.gov.br/ $\mathrm{pub} / \mathrm{td}$.

Preusse, H. (2001), "MERCosur: another failed move towards regional integration?", The World Economy: The Leading Journal on International Economic Relations, vol. 24, Wiley.

Sarti, F. (2001), "Internacionalização comercial e produtiva no MERCosul nos anos 90", tesis, Campinas, Universidad Estadual de Campinas.

Senhoras, E.M. (2005), "A indústria automobilística sob enfoque estático e dinâmico: uma análise teórica", VIII SemeAd, São Paulo, Facultad de Economía, Administración y Contabilidad/ Universidad de São Paulo (FEA/USP).

Sica, D. (2005), "La realidad de la industria automotriz en el camino hacia la consolidación?", Buenos Aires, Salón Internacional del Automóvil.

Tigre, P. y otros (1999), "Impacto del mercosur en la dinámica del sector automotor", Impacto sectorial de la integración en el MERCOSUR, J.J. Taccone y L.J. Garay (orgs.), Buenos Aires, Banco Interamericano de Desarrollo/Instituto para la Integración de América Latina (BID/INTAL) [en línea] www. iadb.org/Intal/ aplicaciones/uploads/.

Viner, J. (1950), The Customs Union Issue, Nueva York, Carnegie Endowment for International Peace.

Yeats, A. (1997), "Does MERCOSUR's trade performance raise concerns about the effects of regional trade arrangements?", Policy Research Working Paper, $\mathrm{N}^{\circ} 1729$, Washington, D.C., Banco Mundial. 